\title{
On Chinese Idiom Translation from Cultural Perspective
}

\author{
Lin Xue and Chuntao Han \\ Department of Foreign Language Studies \\ University of Science and Technology Beijing \\ Beijing China \\ ustbxuelin@163.com
}

\author{
Ning Cai \\ North-west University of Nationalities \\ Lan Zhou, China \\ caining91@tsinghua.org.cn
}

\begin{abstract}
Translation is a cultural interaction in nature. Chinese idiom is a unique linguistic form and the crystallization of national culture. Its rich source--historical events, the fable story, literary works and daily life-determines that the Chinese idioms carry rich cultural connotation. Due to the special linguistic form and abundant cultural connotation, Chinese idiom translation is a complex processing. This artide analyzes Chinese idiom translation from cultural perspective.
\end{abstract}

Keywords- cultural perspective; idiom; idiom translation

\section{INTRODUCTION}

Language is the externalization and characterization of culture, while idioms can be regarded as typical characterization of local culture. Chinese four-characteridiom is a ready-made formulaic unit representing the typical feature of Chinese culture. Idiom has a fixed structure and a fixed meaning as a whole. Chinese idioms are accumulated through the long history of Chinese civilization. Thus rich cultural connotation, cultural characteristics, and cultural background information are embedded in them. They are closely associated with surroundings, life history, and social institutions of the native speakers. So in terms of cultural characters of language, idioms are undoubtedly more typical than any other language forms.

It is generally admitted that language is bond with culture. Language is a product of social and cultural development, thus no language can be separated from its cultural background. On the other hand, culture is embedded in the language which is used for communication. Language represents and symbolizes a unique culture. Different languages load different cultures. Then, translation, as a dynamic process of rendering languages, undertakes the mission of conveying cultural connotations contained in languages. That is why so many scholars both at home and abroad have paid much attention to the cultural connotations in translation in recent years. In America, the cultural turn in translation was initially marked by Robert Lado in 1957. In 1990, American scholar Andre Lefevere and British scholar Susan Bassnett suggested that translation studies take a "cultural turn" and look forward to the work of cultural studies scholars. They researched the history of translation of both the West and China and concluded that translation practice has been under the influence of some cultural factors like the role of ideology, the power of patronage, central texts and central cultures, etc. Therefore, the close relation between language and culture determines the close bound between culture and translation. Similarly, this relation is reflected in Chinese idiom translation.

The principle of cultural translation is taking a variety of forms to reproduce the source cultural information in the target language as much as possible to realize the equivalent transmission between languages. In terms of idioms translation problem, many translators tend to borrow existing idioms in English language, ignoring the special cultural connotations and charms of the source language. Trying to reveal the cultural connotations and charm of the Chinese idioms consciously to the foreigners is quite a meaningful activity of culture interaction.

\section{SOME VOICES OF CULTURE AND TRANSLATION}

The well-known translation theorist, Eugene A.Nida believes that culture is "the totality of beliefs and practices of a society.” (1993:105)

Culture covers a wide range of human life and behavior. Culture is the criterion deriving from people's shared experience of life and studies, and it's the standard for people to evaluate their use of language.

More and more scholars and translators have come to realize the complexity of translation and do not just limit their study within the perspective of linguistics any more. Just as what Andre Lefevere said, "It is my conviction that translations are made under a number of constraints of which language is arguable the least important." (2004: xii)Translation now is referred to as a cross-cultural, crosslinguistic, and cross-social commun ication event. The goal and features of translation are to exchange concepts and cultures connotations. In order to reveal the close relationship between culture and translation, Holz Mantari used "intercultural cooperation", Christiane Nord replaced translation with "intercultural communication", and Andre Lefevere viewed it as acculturation".

Robert Lado calls the social cultural characteristic of a language as the blind side in the cultural communication and the teaching and learning activity. It can be concluded that Linguistics Across Culture lays a theoretical foundation for the culture turn in translation study (Lado,1957).

Robert Lado pointed that foreign language learners tend to try to understand and use the language in the form and meaning of their mother tongue. Thus, misunderstanding might easily appear in cultural 
interaction. Lado defined culture as a special mode of behavior in a specific circumstance. He called this behavior as cultural behavior and called the understanding of cultural behavior as cultural understanding. The cultural understanding is the basis of translation.

In 1990, Andre Lefevere and Susan Bassnett put forward "cultural turn in translation" which indicates that the basic unit of translation is culture. In their book Constructing Cultures, they present a convincing example for moving the field of cultural studies closer to translation. As Bassnett and Lefevere argue in Constructing Cultures, the study of translation is the study of cultural interaction" (Edward Gentzler,2001 : ix) Bassnett and Lefevere are pioneers of "cultural turn" in translation studies. In 1976, Lefevere formally suggested "Translation Studies" as the name of the discipline of translation at an international translation conference. Dating back to 1990, it was he and Bassnett who formally pointed out the developing direction of transition towards "cultural turn" in their book Translation, History, and Culture. Since then, more and more scholars and researchers in the field have been greatly influenced and gradually began to change their study from linguistics view to culture view.

Accordingly, cultural studies and translation studies have been developing in parallel ways. Now it is time for them to jump out of their own orbits and unite to develop together. Just as what Lefevere says,

"Knowledge of the translation, the genealogy of our thinking, helps us to focus not just on problems concerning translation as such, but also ways in which the study of translation can be made productive for cultural studies in general. It is finally realized that translation deserves to occupy a much central position in cultural history than the one to which it is currently relegated." (2004: xii)

In China, there are many scholars like Tan Zaixi (1986), Jin Huikang (1999), Bao Huinan (2007), who made researches and publish articles and books to demonstrate the important role that cultural understanding plays in translation. As early as in the twenties and thirties in the 20th century, Mr. Luxun indicated that translation should tend to be Europeanized and have the foreign temperament in order to keep the source text's flavor and culture. In 1980s, Mr. Wang Zuoliang began to make great efforts to suggest the combination of translation studies with cultural studies. To some extent, he indirectly put forward the theory of "cultural Equivalence" in his book Culture and Translation. He says,

"Translation equivalence in its sense should be matched in meanings, functions, scopes, feelings and impacts in the two cultures." (1991: 1)

So, the goal of translation is to create equivalence in culture and equivalences in meanings, functions, etc. between two languages. Besides, one's cultural knowledge is crucial to comprehensive and correct understanding of linguistic materials. A good translation must be based on the combination of social, cultural and linguistic foundations.

\section{CHINESE IDIOMS AND T HEIR CULTURAL FEATURES}

Language is the characterization of culture, while idioms can be regarded as typical characterization of local culture, which is the pearl of language. Chinese idioms are accumulated through the long history of Chinese civilization. Thus rich cultural connotation, cultural characteristics, and cultural background information are embedded in them. Chinese idioms contain large number of metaphoric figures, which reflect the local culture. They are closely associated with surroundings, life history, and culture of the native speakers. So when cultural characters of language is being talked about, id ioms are undoubtedly more typical than any other language form.

Just as it is difficult to define "culture", it is uneasy to give a clear-cut definition to " idiom" , for it can be defined in various ways. Oxford dictionary defines it as follows :

Phrase or sentence whose meaning is not clear from the meaning of its individual words and which must be learnt as a whole unit. (1997: 734)

Longman gives such a definition:

a group of words with a special meaning which is different from the meaning of the individual words. (2005: vii)

Cihai defines it as follows:

A kind of idio matic phrase, which is used out of habit for a long history, has brief form and brilliant meaning. Most of them are fixed phrases, clauses, or even a sentence. Chinese idioms mostly are four-character phrases, organized variously, and source-diversified. Some can be understood literally. Some cannot be understood literally, unless readers have the knowledge of their sources. (1979)

In spite of the differences in definition to a Chinese idiom, the common features are clearly shown.

First, an idiom can be a phrase, a clause or even a sentence, which has a fixed form. Its structure is fixed as a completed whole unit. Any change to the idioms makes them meaningless. That is to say, stability and wholeness are characteristic of idioms. Second, an idiom must be learned as a whole unit and cannot be separated although it can have different tense forms .

In spite of the generally-accepted definition and criteria for idioms, dictionaries divide idioms into different forms. In the author's point of view, the form of Chinese idiom mainly includes set phrases, proverbs and Xiehouyu. Set phrases mostly are four-character idioms, such as xingfengzuolang dahailaozhen and minglieqianmao. Proverbs are clauses or even sentences, which usually contain some widespread truth. For example, tianxiawuyayibanhei means that all the bad persons in the world share the same characteristics. Xiehouyu is usually a short sentence, whose meaning is shown in its answering phrase. For example, gounahaozi-duoguanxianshi means that dog catches rats - dog does something which it does not need to do.

Chinese idioms are sort of fixed and even frozen in structure, but widely denoted in meaning, providing rich information to a people's history, religion, geography, social views and values, etc. And many of them are rhetorically contained, directing to all walks of life.

From all the above, it can be seen that aspects of culture have been planted into idioms. As the pearl of language, idioms reflect people's attitude towards the society they live in and record their history and conception of life throughout dynasties. 
Since idiom is such a complex phenomenon in language, it will bring difficulty and pose harsh obstacles to our translating practice. That is the very topic which will be coped with in the next chapter as to how to translate Chinese idioms accurately and culturally into English.

\section{TRANSLATION TECHNIQUES OF CHINESE IDIOMS}

The principle of cultural translation is taking a variety of forms to reproduce the source cultural information in the target language as much as possible to realize the equivalent transmission between languages. When I deal with the Chinese idioms translation problem, many translators tend to borrow existing idioms in English language, ignoring the special cultural connotations and charm of the source language. Here, the author does not blindly go against this approach of applying and borrowing the existing English idioms, but try to reveal the cultural connotations and charm of the Chinese idioms consciously to the foreigners is quite a meaningful activity of culture interaction. It is needed to avoid applying and borrowing idioms to translate Chinese idioms, but try to keep the primitive flavor of Chinese language and culture.

From all the scholars in the translation field, the author realizes that translation is a process of cultural interaction. Nowadays, the communication between cultures has become more frequent than before, which requires people not only regard their own culture as the central culture, but try to absorb more foreign culture to fulfill the crossculture translation practice. With this in mind, the author advises that people should combine literal translation and free translation, and apply these techniques flexibly into different circumstances. Besides, there are some idioms both in Chinese and English sharing the similar imagery and culture information. In this situation, equivalent translation (Eugune A.Nida:1967) can be taken as the main method to promote the understanding of Chinese idioms for the foreigners.

\section{A. The Application of Equivalent Translation on Idiom Translation}

People around the world are living on the only planet and have experienced similar material development phase. The physical world, social development, human thinking and emotion form the communication and compatibility of various cultures and languages. Some idioms both in English and Chinese in language forms and the metaphoric image share striking rese mblances. Anyhow, some English idioms can be borrowed directly so that English readers will be able to get the correct meaning and vivid feeling of the idioms. For example, tongchoujiangu is translated as "making overall plans and taking all facts into consideration", of which the corresponding idiom "take all facts into consideration" in English is used in this translation version. Other examples are given below:

Gegeburu - to be like square pegs in round holes

Minglieqianmao - stand first on the list

Chenredatie - to strike while the iron is hot

Turuqilai-come all of a sudden

Dajingxiaoguai - make a fuss oversomething

Xiangyuerqi - weep all alone in a corner
However, because of the differences in living environment, religion, and customs between the Chinese culture and English culture, the form and expressing ways of the languages differ in a few aspects. For the Chinese farming culture, the land was the main means of production for the ancient Chinese farmers, so there are many id ioms are related with land (or earth). Britain is an is land nation, of which shipping has been Ill developed, so English idioms related to water more. For example, the idiom huijinrutu seems to have the corresponding idiom "spend money like water". Although the two idioms differ slightly in the expressing way, the metaphorical meaning they convey is basically the same. So id ioms of this kind can be translated in the principle of equivalent translation. Some other examples are given below:

Feimuniubuxiangji - a horse of another color

Ningweijitou,buweifengwei-better be the head of a dog than the tail of a lion

Dongruoguanhuo - as clear as daylight

Yipinruxi - as poor as a church mouse

Hezeeryu - kill the goose that lays the golden eggs

\section{B. The Application of Literal Translation on Idiom Translation}

Quite a few Chinese idioms do not have corresponding idioms in English, but its implied meaning is rather obvious or easy to be deducted. Even some Chinese idioms can be understood by their literal meaning and share their metaphorical connotation with their literal ones. In this situation, under the premise without affecting the original meaning, literal translation can better preserve the cultural dements and national characteristics of the source language. Mr. Liu Zhongde says, "Superficially speaking literal translation means not to alter the original words and sentences ; strictly speaking, it strives to keep the sentiments and style of the original."(1998: 49) When dealing with this kind of idioms, literal translation is the first choice. For example, Qizuibashe can be translated as "with seven mouths and eight tongues". This version not only preserves the original image, but also keeps the rhetorical effect of the Chinese four-character idioms. Similar examples are given below: back

Zoumaguanhua-looking at the flowers on the horse

Dacaojingshe - beat the grass and startle the snake

Kegumingxin - to be engraved on one's heart and bones

Zuoshanguanhudou-sitting on the top of the mountain to watch the tigers fight

Jiedaosharen - murder with a borrowed knife

Diaohulishan - to lure the tiger from the mountain

Banmennongfu - to show off one's proficiency with the axe before $\mathrm{Lu}$ Ban the master carpenter

Gongqibubei - to strike someone when he is unprepared

\section{The Application of Free Translation on Idiom Translation}

Not all the Chinese idioms have the corresponding ones in English, and can be translated literally. Some metaphorical images cannot be accepted by the English readers for the cultural gap. In other words, a number of 
English idioms carry partially or even entirely different cultural images or implications with Chinese. In this case, free translation can be used. For example, if meifeisewu is translated as "one's eye-brows are flying and his countenance is dancing", the readers cannot understand the real meaning of it. However, if it is translated as "to beam with joy", the effect can be much better for the readers to get the connotation of it. For example:

Zhulandashuiyichangkong - all in vain

Denghongjiulv - dis sipated and luxurious

Chedaoshanqianbiyoulu - It is always darkest before dawn.

Wukongburu - to take advantage of every weakness

Kaimenjianshan - to come straight to the point

Fengyupiaoyao-(a situation) being unstable

Chouxinzhife - to extirpate an evil by the root

Huabingchongji-feed on illusion

Free translation simply indicates the implied meaning of the idioms directly. Thus, some original figures and images are lost during the translation process. In this way, the foreign readers can easily get in the connotation buried in these idioms, but they have no chance to chew the primitive flavor of the idioms. In order to solve this problem, the author will discuss literal plus free translation.

\section{Literal plus Free Translation application}

In order to render the original meaning of the source idioms accurately and effectively and transplant the Chinese culture into English, the author takes literal plus free translation as the main technique when encountering those culture-rich and images-rich Chinese idioms. At first, the author needs to translate those idioms literally to transplant the source images. Then, the author takes the free translation as an assistance to transplant the cultural connotation. At last, the author should polish the words to realize a successful transplant of the Chinese culture. For example, shisirugui should be translated as "looking on death without flinching". "looking on death" is literally translated from "shisi"; "Without flinching" denotes "No fear and cower." is freely translated from "rugui". This combination makes the translation version easier for English readers to understand all the information buried in the idiom. Other examples are given below:

Zoumaguanhua - look at the flowers while riding on the back of galloping horse, give a cursory glance

Wuqinwugu - without a single relative or friend to turn to

Bugaoerbie - take French leave

So, the rendition by this method not only keeps the original image of the source language, but perfectly reveals the implied meaning. The literal plus free translation can be adopted when the corresponding figuration is absent in English or when the corresponding English figuration lacks convenience and vividness.

\section{CONCLUSION}

Language is the accumulation and reflection of a people's culture and history. Translation acts as the bridge between two different cultures. This study focuses on the source of the Chinese idioms, their cultural connotation and the basic translation principles and methods to analysis how to deal with the culture information involving in the translation practice. On one hand, I should retain the exotic flavor and the special mode of expression of the source language. On the other hand, I must make sure that the reader can take in the translation version easily. This research paper, combining the Culturological ideas of Andre Lefevere and other scholars with the cultural characteristics of Chinese idioms, tentatively explores four practicable translating methods of Chinese idioms : equivalent translation, literal translation, free translation and literal plus free translation, and the principles of applying them.

In order to transfer Chinese idioms' cultural information to English and promote the interaction between English and Chinese cultures, the "literal translation" should be the first choice for us to translate Chinese idioms. If there is absolutely no corresponding idioms in English, the liberal translation may be a proper choice. But at the most time, it is much better to take "literal plus free translation" so as to retain the cultural information and the original figure of speech as much as possible. Although the aesthetic effects may have been weakened by the adoption of the combination of the two translation techniques, it can still be regarded as the most effective method. In a word, whether the author should adopt literal translation, free translation or literal plus free translation depends on the cultural relationship between the source language and the target language. Chinese and English have similarities and differences in ways of expression. The proper translation method should be adopted according to the concrete situations and specific context.

In conclusion, the four translation methods of Chinese idioms are overlap and inter-complementary. The author does not approve of the irrenderability of culture-loaded terms, nor does the author escape from the translating difficulty brought by the cultural gap between the two languages.

\section{REFERENCE}

[1] Bassnett, Susan \& Lefevere, Andre. Constructing Cultures-Essays on Literary Translation. Shanghai: Shanghai Foreign Language Education Press 2005.

[2] Fernando, Chitra. Idioms and Idiomaticity, Oxford University Press; Shanghai: Shanghai Foreign Language Education Press.1996

[3] A Dictionary of English Allusions. Beijing: The Commercial Press.2005

[4] A Dictionary of English idioms. Shanghai: Shanghai Ancient Books Printing House. 1999

[5] Collins Dictionary of the English Language. London: Collins.1979

[6] Gentzler, Edward . Foreword of Cultural Construction. Shanghai: Shanghai Foreign Language Education Press. 1979

[7] Gentzler, Edwin. Contemporary Translation Theories, Shanghai: Shanghai Foreign Language Education Press.2004

[8] Lefevere, Andre. Translation/History/Culture. Shanghai(pp. 71-73): Shanghai Foreign Language Education Press. 2004

[9] Nida E. A.Language, Culture, and Translating. Shanghai: Shanghai Foreign Language Education Press. 1993

[10] Tylor,E. B. Primitive Culture. New York: Brentanos.1871 . 